\title{
Effectiveness of continuous glucose monitoring in maintaining glycaemic control among people with type 1 diabetes mellitus: a systematic review of randomised controlled trials and meta-analysis
}

\author{
Evelyn Teo ${ }^{1}$ (D) $\cdot$ Norasyikin Hassan ${ }^{2}$ (D) $\cdot$ Wilson $\operatorname{Tam}^{1}$ (D) Serena Koh ${ }^{1}$ (D) \\ Received: 23 July 2021 / Accepted: 2 November 2021 / Published online: 9 February 2022 \\ (C) The Author(s), under exclusive licence to Springer-Verlag GmbH Germany, part of Springer Nature 2022
}

\begin{abstract}
Aims/hypothesis The aim of this work was to assess the effectiveness of continuous glucose monitoring (CGM) vs selfmonitoring of blood glucose (SMBG) in maintaining glycaemic control among people with type 1 diabetes mellitus.

Methods Cochrane Library, PubMed, Embase, CINAHL, Scopus, trial registries and grey literature were searched from 9 June 2011 until 22 December 2020 for RCTs comparing CGM intervention against SMBG control among the non-pregnant individuals with type 1 diabetes mellitus of all ages and both sexes on multiple daily injections or continuous subcutaneous insulin infusion with $\mathrm{HbA}_{1 \mathrm{c}}$ levels, severe hypoglycaemia and diabetic ketoacidosis (DKA) as outcomes. Studies also included any individual or caregiver-led CGM systems. Studies involving GlucoWatch were excluded. Risk of bias was appraised with Cochrane risk of bias tool. Metaanalysis and meta-regression were performed using Review Manager software and R software, respectively. Heterogeneity was evaluated using $\chi^{2}$ and $I^{2}$ statistics. Overall effects and certainty of evidence were evaluated using $Z$ statistic and GRADE (Grading of Recommendations, Assessment, Development and Evaluation) software.

Results Twenty-two studies, involving 2188 individuals with type 1 diabetes, were identified. Most studies had low risk of bias. Meta-analysis of 21 studies involving 2149 individuals revealed that CGM significantly decreased HbA $1 \mathrm{c}$ levels compared with SMBG (mean difference $-2.46 \mathrm{mmol} / \mathrm{mol}[-0.23 \%]$ [95\% CI $-3.83,-1.08], Z=3.50, p=0.0005$ ), with larger effects experienced among higher baseline $\mathrm{HbA}_{1 \mathrm{c}}>64 \mathrm{mmol} / \mathrm{mol}(>8 \%)$ individuals (mean difference $-4.67 \mathrm{mmol} / \mathrm{mol}[-0.43 \%][95 \% \mathrm{CI}$ $-6.04,-3.30], Z=6.69, p<0.00001)$. However, CGM had no influence on the number of severe hypoglycaemia $(p=0.13)$ and DKA events $(p=0.88)$. Certainty of evidence was moderate.

Conclusions/interpretation CGM is superior to SMBG in improving glycaemic control among individuals with type 1 diabetes in the community, especially in those with uncontrolled glycaemia. Individuals with type 1 diabetes with $\mathrm{HbA}_{1 \mathrm{c}}>64 \mathrm{mmol} / \mathrm{mol}(>8 \%)$ are most likely to benefit from CGM. Current findings could not confer a concrete conclusion on the effectiveness of CGM on DKA outcome as DKA incidences were rare. Current evidence is also limited to outpatient settings. Future research should evaluate the accuracy of CGM and the effectiveness of CGM across different age groups and insulin regimens as these remain unclear in this paper. PROSPERO registration Registration no. CRD42020207042.
\end{abstract}

Funding This research received no specific grant from any funding agency in the public, commercial or not-for-profit sectors.

Keywords Continuous glucose monitoring $\cdot$ Glycaemic control $\cdot$ Meta-analysis $\cdot$ Self-monitoring of blood glucose $\cdot$ Systematic review - Type 1 diabetes

Evelyn Teo

e0203427@u.nus.edu

Serena Koh

serena_koh@nus.edu.sg

1 Alice Lee Centre for Nursing Studies, Yong Loo Lin School of Medicine, National University of Singapore, Singapore, Republic of Singapore

2 Nursing, Changi General Hospital, Singapore, Republic of Singapore

$\begin{array}{ll}\text { Abbreviations } & \\ \text { CGM } & \text { Continuous glucose monitoring } \\ \text { CSII } & \text { Continuous subcutaneous insulin infusion } \\ \text { DKA } & \text { Diabetic ketoacidosis } \\ \text { GRADE } & \text { Grading of Recommendations, Assessment, } \\ & \text { Development and Evaluation } \\ \text { isCGM } & \text { Intermittent-scanning CGM }\end{array}$

Abbreviations

CGM Continuous glucose monitoring

CSII Continuous subcutaneous insulin infusion

DKA Diabetic ketoacidosis

isCGM Intermittent-scanning CGM 


\section{Research in context}

\section{What is already known about this subject?}

- As diabetic complications remain the predominant cause of mortality among individuals with type 1 diabetes mellitus, it is imperative for these individuals to obtain adequate glycaemic control; a key method is through glucose monitoring

- Current reviews regarding the efficiency of continuous glucose monitoring (CGM) and self-monitoring of blood glucose (SMBG) in maintaining glycaemic control revealed methodological limitations

\section{What is the key question?}

- How effective is CGM vs SMBG in maintaining glycaemic control among people with type 1 diabetes?

\section{What are the new findings?}

- An individual's baseline $\mathrm{HbA}_{1 c}$ levels significantly affected the effectiveness of CGM: compared with SMBG, individuals with poor glycaemic control $\left(\mathrm{HbA}_{1 \mathrm{c}}>64 \mathrm{mmol} / \mathrm{mol}[>8 \%]\right)$ using $\mathrm{CGM}$ experienced greater $\mathrm{HbA} A_{1 c}$ reduction than those with relatively adequate glycaemic control

- Results from meta-regression indicated that individuals with type 1 diabetes with $\mathrm{HbA} \mathrm{Ac}_{1 \mathrm{c}}>64 \mathrm{mmol} / \mathrm{mol}(>8 \%)$ would benefit most from CGM usage

- GRADE certainty of evidence was moderate, which further encourages clinicians to recommend CGM instead of SMBG for individuals with type 1 diabetes mellitus, especially those with poor glycaemic control

\section{How might this impact on clinical practice in the foreseeable future?}

- This study may offer a step forward in the future of diabetes care, especially among individuals with type 1 diabetes with poor glycaemic control $\left(\mathrm{HbA}_{\mathrm{Ic}}>64 \mathrm{mmol} / \mathrm{mol}[>8 \%]\right)$ as they are expected to benefit most from CGM

$\begin{array}{ll}\text { MARD } & \text { Mean absolute relative difference } \\ \text { MD } & \text { Mean difference } \\ \text { MDI } & \text { Multiple daily injections } \\ \text { P-CGM } & \text { Professional CGM } \\ \text { PRISMA } & \text { Preferred Reporting Items for Systematic } \\ & \text { Review and Meta-analysis } \\ \text { RevMan } & \text { Review Manager } \\ \text { RT-CGM } & \text { Real-time CGM } \\ \text { SMBG } & \text { Self-monitoring of blood glucose }\end{array}$

\section{Introduction}

Type 1 diabetes is an emerging global epidemic with a rising incidence rate worldwide [1]. Despite its lower prevalence relative to type 2 diabetes, the annual economic cost of type 1 diabetes to the American healthcare system is significantly higher and costs approximately US $\$ 14.4$ billion [2]. This economic burden could be attributed to rising insulin costs and costly type 1 diabetes complications [3]. These complications remain the predominant cause of death among the type 1 diabetes population [4]. The landmark DCCT trial reported that intensive insulin therapy delayed the onset of diabetic complications but tripled the risk of severe hypoglycaemia [5]. Since individuals with type 1 diabetes depend on such therapies for survival [6], the recommended goal is to maintain near-normal glucose levels [5]. The key to achieving such a glycaemic target is glucose monitoring [7].

In traditional self-monitoring of blood glucose (SMBG), a glucometer measures blood glucose levels in a capillary blood sample drawn via finger-pricking [8]. SMBG has some disadvantages: (1) it is user-dependent and cannot capture nocturnal and asymptomatic hypoglycaemia; (2) it cannot predict impending hypoglycaemia as the single-instant reading offers no information regarding the direction of changing glucose; and (3) this method is susceptible to user error, such as contaminated fingers [9]. Such limitations can be overcome by using continuous glucose monitoring (CGM) [10]. CGM involves a sensor inserted subcutaneously that automatically measures an individual's interstitial glucose levels around the clock [11]. CGM can predict impending hypoglycaemia and can alert and detect glycaemic fluctuations, based on glucose trends and retrospective and real-time data generated [12]. Three types of CGM systems exist: professional CGM (P-CGM); real-time CGM (RT-CGM); and intermittent-scanning CGM (isCGM). Each system varies slightly in terms of function. 
$\mathrm{HbA}_{1 \mathrm{c}}$ remains the gold standard for assessing glycaemic control and is a surrogate marker for longterm diabetic complications risk [13]. However, reviews on the effectiveness of CGM in controlling this variable have revealed research gaps. Methodological limitations were found in ten similar reviews with meta-analysis [14-23] and findings in two were heavily limited by a small sample size $[14,18]$. Studies have shown that a small number of included studies in a meta-analysis yields low statistical power which affects overall findings [24]. Moreover, only four of the reviews included a grey literature search [19-21, 23]. This may have contributed to inaccurate effect-size estimates and publication bias that skewed the meta-analysis results [25]. Furthermore, to our knowledge, only one review [20] included the latest CGM technology (i.e. isCGM) in its pooled analysis as it was only introduced in 2017 [26]. However, the search strategy in the review was heavily limited to only two bibliographic databases, thus introducing potential publication bias [27]. Additionally, the effectiveness of isCGM remains unclear in the review as subgroup analysis was not made possible when only one study utilised isCGM. We therefore undertook a systematic review to address the current research gaps. This review provides an update on the latest review by Langendam et al [19], which is the most similar to this review in terms of population, intervention, comparator and outcome. Findings from this review may benefit healthcare practitioners who are interested in diabetes management and current and future research. Currently, CGM research plays an integral part in artificial pancreas development, where a CGM sensor can automatically drive insulin delivery [28]. This paper aims to assess the effectiveness of CGM vs SMBG in maintaining glycaemic control in the type 1 diabetes population.

\section{Methods}

This systematic review adhered to the Preferred Reporting Items for Systematic Reviews and Meta-analysis (PRISMA) statement [29]. The present review was registered on the International prospective register of systematic reviews (PROSPERO registration no. CRD42020207042).

\section{Data sources and searches}

A three-step search strategy was employed. In the first step, five bibliographic databases (CINAHL, The Cochrane Library, Embase, PubMed and Scopus) were searched for relevant published journal articles. Relevant subject headings, keywords, and syntax rules were incorporated and truncated according to each database to ensure sensitivity [27]. Search terms used in this study are shown in electronic supplementary material (ESM) Table 1. The second step involved searching for relevant ongoing and unpublished trials in trial registries (CentreWatch, ClinicalTrials.gov, CENTRAL, ISRCTN registry and WHO ICTRP). Grey literature (ProQuest Dissertations and Theses Global) and diabetes-related specialist databases (ADA and International Journal of Diabetes and Clinical Research) were also searched. Last, reference lists of included trials, (systematic) reviews and meta-analyses were searched to obtain more studies. Authors of studies with missing information and inaccessible full text were contacted. Searches were conducted in English from 9 June 2011 onwards since this review is an update of another review [19] where the authors stopped their search on 8 June 2011. Date restriction was placed to prevent duplication of findings [27].

\section{Eligibility criteria and study selection}

Studies were included if they met the following criteria: (1) non-pregnant individuals of all ages and both sexes with type 1 diabetes mellitus who were on an intensive insulin therapy regimen (multiple daily injections [MDI] of insulin or continuous subcutaneous insulin infusion [CSII]); (2) any individual/caregiver-led CGM systems; (3) SMBG as control; (4) post-intervention $\mathrm{HbA}_{1 \mathrm{c}}$ level, severe hypoglycaemia event (defined as requiring assistance from another person to administer carbohydrate, glucagon or other resuscitative actions because of altered consciousness) and diabetic ketoacidosis (DKA) events as outcomes; and (5) RCTs. Studies involving GlucoWatch were excluded as this device is no longer available [30]. The full eligibility criteria are found in ESM Table 2. The four-stage PRISMA flow diagram guided the selection process [29]. First, search results from bibliographic databases and additional sources were downloaded into EndNote X9 (version 9.3.3) software and any duplicates were removed [31]. Second, two reviewers (ET and SK) independently screened the abstracts and/or title against eligibility criteria and removed irrelevant articles. Potentially relevant articles were retrieved as full texts. Articles covering the same study were linked. Third, ET and SK independently reviewed the full-text articles against the eligibility criteria and excluded ineligible studies. Last, ET and SK validated the final list of all included studies. A third reviewer $(\mathrm{NH})$ was consulted if disagreements between ET and SK were not resolved through discussion.

\section{Data extraction}

Two reviewers (ET and SK) independently extracted relevant data from all included articles using the standardised Cochrane Data Extraction form [32]. Any discrepancies in extracted data were resolved through discussion with $\mathrm{NH}$. 
The form was initially piloted on six articles to ensure all necessary information was collected. The data obtained included author's details, study design, setting, age, population, sample size, intervention, control, attrition rate, outcomes (specified above) and intention-to-treat analysis. Diabetesrelated specific items, such as CGM systems, SMBG device and baseline $\mathrm{HbA}_{1 \mathrm{c}}$ were extracted.

\section{Risk of bias assessment}

Two reviewers (ET and SK) independently assessed the risk of bias using Cochrane Collaboration's risk of bias tool [32]. The tool consists of six domains: (1) random sequence generation; (2) allocation concealment; (3) blinding of participants and personnel; (4) blinding of outcome assessment; (5) incomplete outcome data; and (6) selective reporting. Any disagreements between the two reviewers were resolved through discussion with $\mathrm{NH}$. The $\mathrm{K}$ statistic was measured using GraphPad software [33]. The risk of bias graph and summary were generated by Review Manager (RevMan) software version 5.4 [34].

\section{Data synthesis and analysis}

The primary outcome was post-intervention $\mathrm{HbA}_{1 \mathrm{c}}$ level; the secondary outcomes were post-intervention severe hypoglycaemia and DKA events. The primary outcome was expressed as mean difference (MD) with $95 \%$ CI. Secondary outcomes were expressed as RR with $95 \%$ CI. Results were deemed statistically significant if $p<0.05$ [32]. Results were pooled using DerSimonian and Laird's random-effect model. RevMan software was used to conduct meta-analyses, data transformation and graph generation. Meta-regression was conducted using the 'metafor' package of $\mathrm{R}$ and the between-study variation was estimated by the Restrict Maximum Likelihood method [35]. A narrative synthesis was used when the meta-analysis was inappropriate.

Heterogeneity was assessed using $\chi^{2}$ and $I^{2}$ statistics. The statistical significance of the $\chi^{2}$ test was set at $p<0.10 . I^{2}$ was interpreted as follows: 0-40\% (unimportant); 30-60\% (moderate heterogeneity); 50-90\% (substantial heterogeneity); and 75-100\% (considerable heterogeneity) [32]. Publication bias was assessed using funnel plot and Egger's test [36].

Subgroup analysis explored the effectiveness of CGM across study duration, duration of diabetes, CGM systems, participants' initial $\mathrm{HbA}_{1 \mathrm{c}}$ level and insulin regimen. Sensitivity analysis was performed to determine the source of heterogeneity [37]. Certainty of evidence was appraised using Grading of Recommendations, Assessment, Development and Evaluation (GRADE) software [38].

\section{Results}

\section{Search results}

Two thousand, one hundred and ninety-one studies from five bibliographic databases were downloaded into EndNote for recording and removal of duplicates; this resulted in 1350 records (ESM Fig. 1). Two reviewers (ET and SK) independently screened these records against the eligibility criteria, and excluded 1104 records based on title and 168 records based on abstracts. Full texts of the remaining 78 articles were retrieved and screened against eligibility criteria, and another 56 articles were excluded for reasons outlined in ESM Fig. 1. The resulting 22 articles were included in this review while 21 articles were pooled into meta-analysis.

\section{Study characteristics}

The characteristics of the 22 included studies involving 2188 participants are summarised in Table 1. Seven studies were crossover designs [39-45]. The remaining 15 studies were parallelgroup designs. All studies were conducted in an outpatient setting. Sample size varied from $20[44,46]$ to 241 [47] participants. Participants' mean baseline $\mathrm{HbA}_{1 \mathrm{c}}$ was either $\leq 64 \mathrm{mmol} /$ $\mathrm{mol}(\leq 8 \%)(n=8)[39,40,47,55-58,60]$ or $>64 \mathrm{mmol} / \mathrm{mol}$ $(>8 \%)(n=11)[41,42,44,46,48-53,59]$. Three studies did not report participant's baseline $\mathrm{HbA}_{1 \mathrm{c}}[43,45,54]$. Insulin delivery was via MDI alone $(n=8)$ [41, 42, 48, 49, 51, 55-57], CSII alone $(n=3)[46,54,58]$ and MDI/CSII $(n=11)[39,40$, $43-45,47,50,52,53,59,60]$. The various CGM systems were P-CGM $(n=2)$ [51, 57], isCGM $(n=2)[47,50]$ and RT-CGM ( $n=18)$. Study duration was $<8$ weeks $(n=3)$ [40, 51, 57], 14 16 weeks $(n=5)[39,43,45,46,48]$ and $>24$ weeks $(n=13)$. Duration of diabetes was $<10$ years $(n=6)$ [ $46,50-52,56,57]$, 10 years to $<20$ years $(n=4)[39,40,48,59], 20$ years to $<30$ years $(n=5)[41,47,49,55,58]$ and $\geq 30$ years $(n=2)$ $[53,60]$. Five studies did not report duration of diabetes [42-45, 54]. The primary outcome (i.e. $\mathrm{HbA}_{1 \mathrm{c}}$ level) was reported in all studies. The secondary outcomes of post-intervention severe hypoglycaemia and DKA events were reported in 13 and 14 studies, respectively.

\section{Quality of included studies}

Risk of bias summary and graph are presented in ESM Fig. 2. A $\kappa$ inter-rater agreement of 0.85 was achieved, demonstrating an almost perfect agreement.

As for random sequence generation, five studies were appraised as unclear risk due to insufficient information [42, $44,51,53,59]$. The remaining 17 studies applied adequate randomisation technique. With regards to allocation concealment, five studies were graded unclear risk due to insufficient information $[44,50,51,53,59]$. All remaining studies except for 


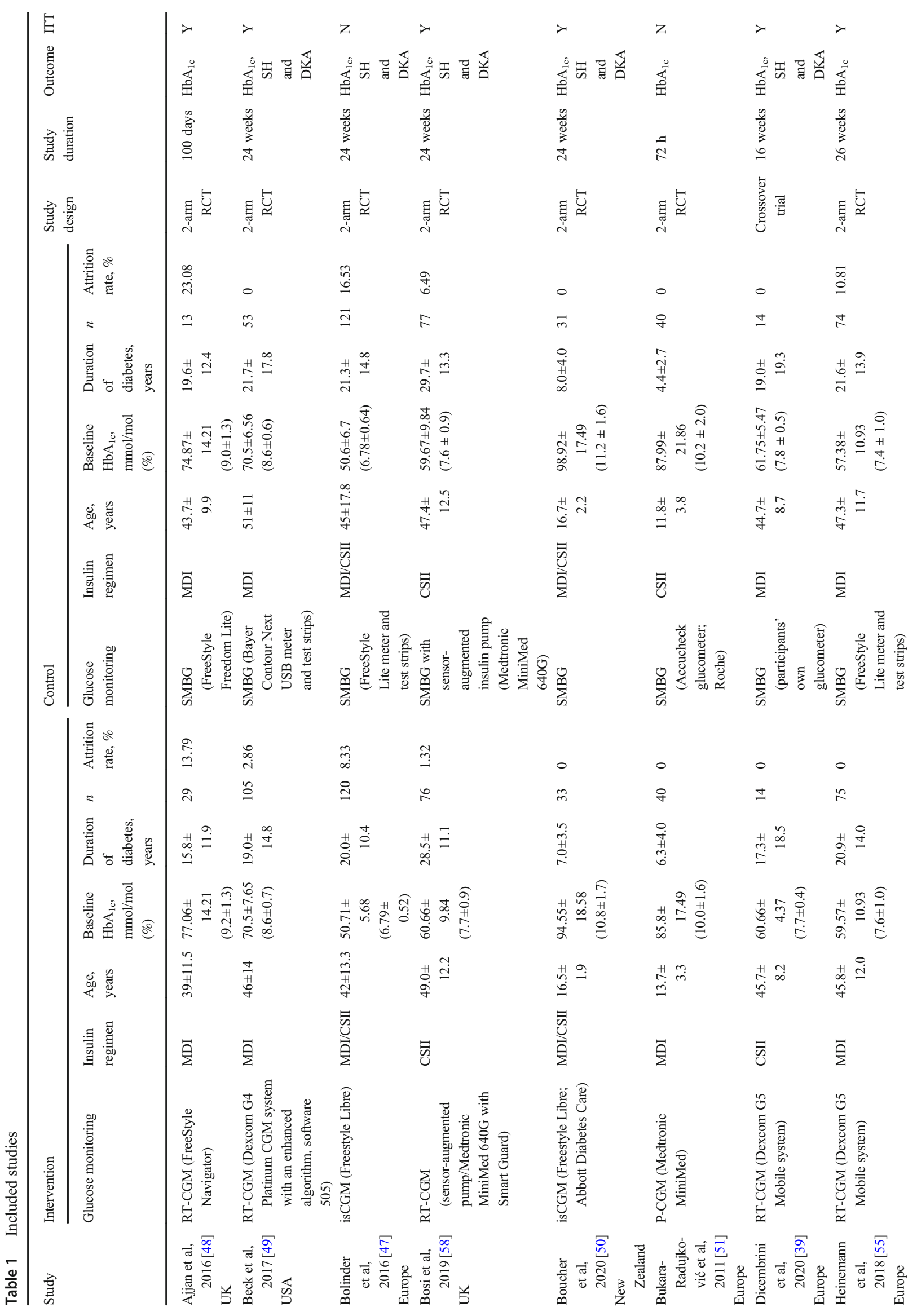




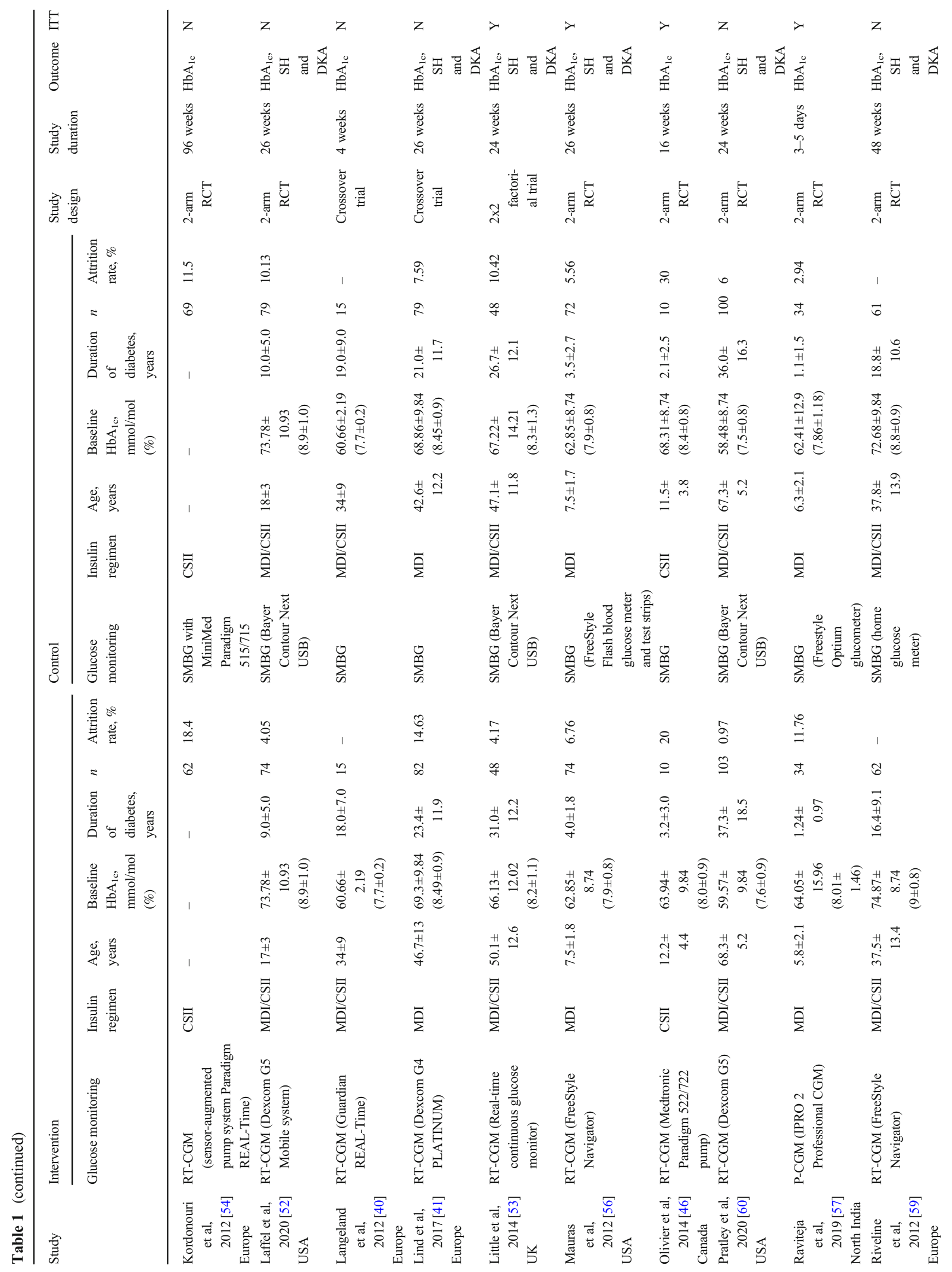




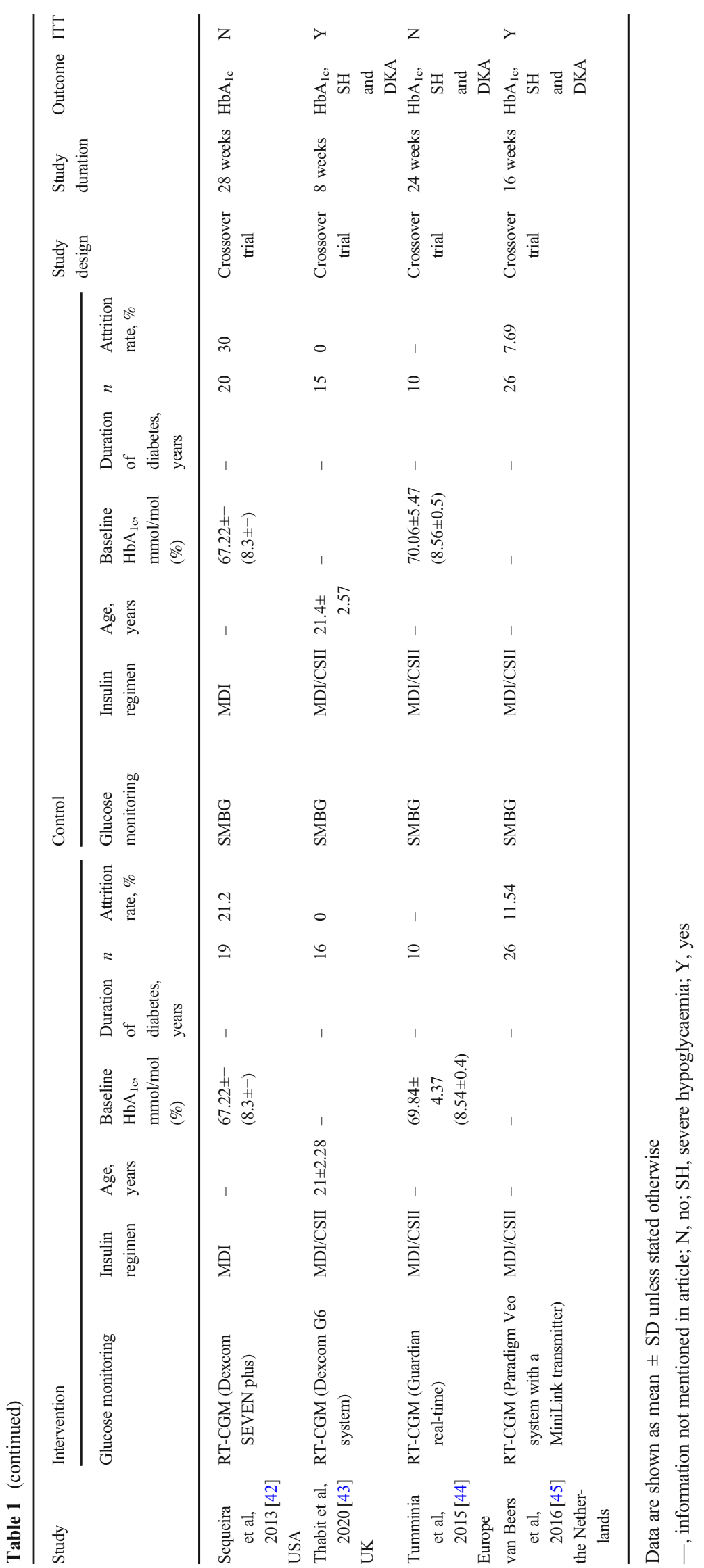


one [47] applied adequate allocation concealment. Due to the nature of intervention (e.g. RT-CGM and isCGM), blinding was not feasible. As the lack of blinding was less likely to influence objective outcomes [61], all 22 studies were graded low risk for blinding of participants, personnel and outcome assessment. For incomplete data, one study [46] was rated high risk as $\geq 20 \%$ attrition rate observed in both arms posed a serious threat to the study's validity [62]. The remaining studies were rated low risk for incomplete data. For selective reporting, 18 studies were rated low risk while four studies [39, 40, 44, 51] lacked clarity, hence were rated unclear risk.

\section{Effectiveness of CGM}

$\mathrm{HbA}_{1 \mathrm{c}}$ Twenty-one studies that assessed the effect of CGM (intervention) vs SMBG (control) on post-intervention $\mathrm{HbA}_{1 \mathrm{c}}$ levels among 2149 participants were pooled into meta-analysis (Fig. 1). Overall, participants using CGM experienced significantly lower $\mathrm{HbA}_{1 \mathrm{c}}$ level $(\mathrm{MD}-2.46 \mathrm{mmol} / \mathrm{mol}$ $[-0.23 \%][95 \% \mathrm{CI}-3.83,-1.08] ; Z=3.50, p=0.0005)$ than individuals using SMBG. Substantial heterogeneity was present $\left(I^{2}=72 \%, p<0.00001\right)$. One trial was not pooled into meta-analysis due to missing data [42]; the study reported an overall non-significant $\mathrm{HbA}_{1 \mathrm{c}}$ reduction when comparing CGM with SMBG.

Severe hypoglycaemia Thirteen studies evaluated the effect of CGM vs SMBG on post-intervention severe hypoglycaemia events among 1546 participants (Fig. 2). CGM demonstrated non-significant decrease in severe hypoglycaemia events (RR 0.61 [95\% CI 0.33, 1.15]; $Z=1.53, p=0.13$ ) when compared with SMBG. Substantial heterogeneity was present $\left(I^{2}=50 \%\right.$, $p=0.04)$.

DKA Fourteen studies evaluated the effect of CGM vs SMBG on post-intervention DKA events among 1644 participants (Fig. 3). CGM intervention demonstrated no significant reduction in DKA events (RR 1.06 [95\% CI 0.49, 2.32]; $Z=0.15$, $p=0.88)$ compared with SMBG. Homogeneity was observed $\left(I^{2}=0 \%, p=0.59\right)$.

\section{Subgroup analyses}

Subgroup analyses were performed for the primary outcome (i.e. $\mathrm{HbA}_{1 \mathrm{c}}$ level). Subgroup analyses were stratified according to the following variables: (1) participants' mean baseline $\mathrm{HbA}_{1 \mathrm{c}}$; (2) insulin regimen; (3) study duration; (4) CGM systems; and (5) duration of diabetes. However, these analyses revealed no significant subgroup difference for study duration ( $p=0.67$ ) (ESM Fig. 3), CGM systems ( $p=0.88$ ) (ESM Fig. 4) and duration of diabetes $(p=0.90)$ (ESM Fig. 5).

Subgroup analysis comparing the effectiveness of CGM among participants with mean baseline $\mathrm{HbA}_{1 \mathrm{c}} \leq 64 \mathrm{mmol} /$ mol $(\leq 8 \%), \mathrm{HbA}_{1 \mathrm{c}}>64 \mathrm{mmol} / \mathrm{mol}(>8 \%)$ and unreported $\mathrm{HbA}_{1 \mathrm{c}}$ reported significant subgroup difference $\left(I^{2}=89.7 \%\right.$, $p<0.0001$ ) (Fig. 4). Among participants with mean baseline $\mathrm{HbA}_{1 \mathrm{c}}>64 \mathrm{mmol} / \mathrm{mol}(>8 \%)$, those using CGM encountered significant reduction in $\mathrm{HbA}_{1 \mathrm{c}}$ level $(\mathrm{MD}-4.67 \mathrm{mmol} / \mathrm{mol}$ $[-0.43 \%]$ [95\% CI $-6.04,-3.30] ; Z=6.69, p<0.00001)$ compared with participants using SMBG. Conversely, CGM did not significantly decrease $\mathrm{HbA}_{1 \mathrm{c}}$ level in individuals with mean baseline $\mathrm{HbA}_{1 \mathrm{c}} \leq 64 \mathrm{mmol} / \mathrm{mol}(\leq 8 \%)(Z=0.61$,

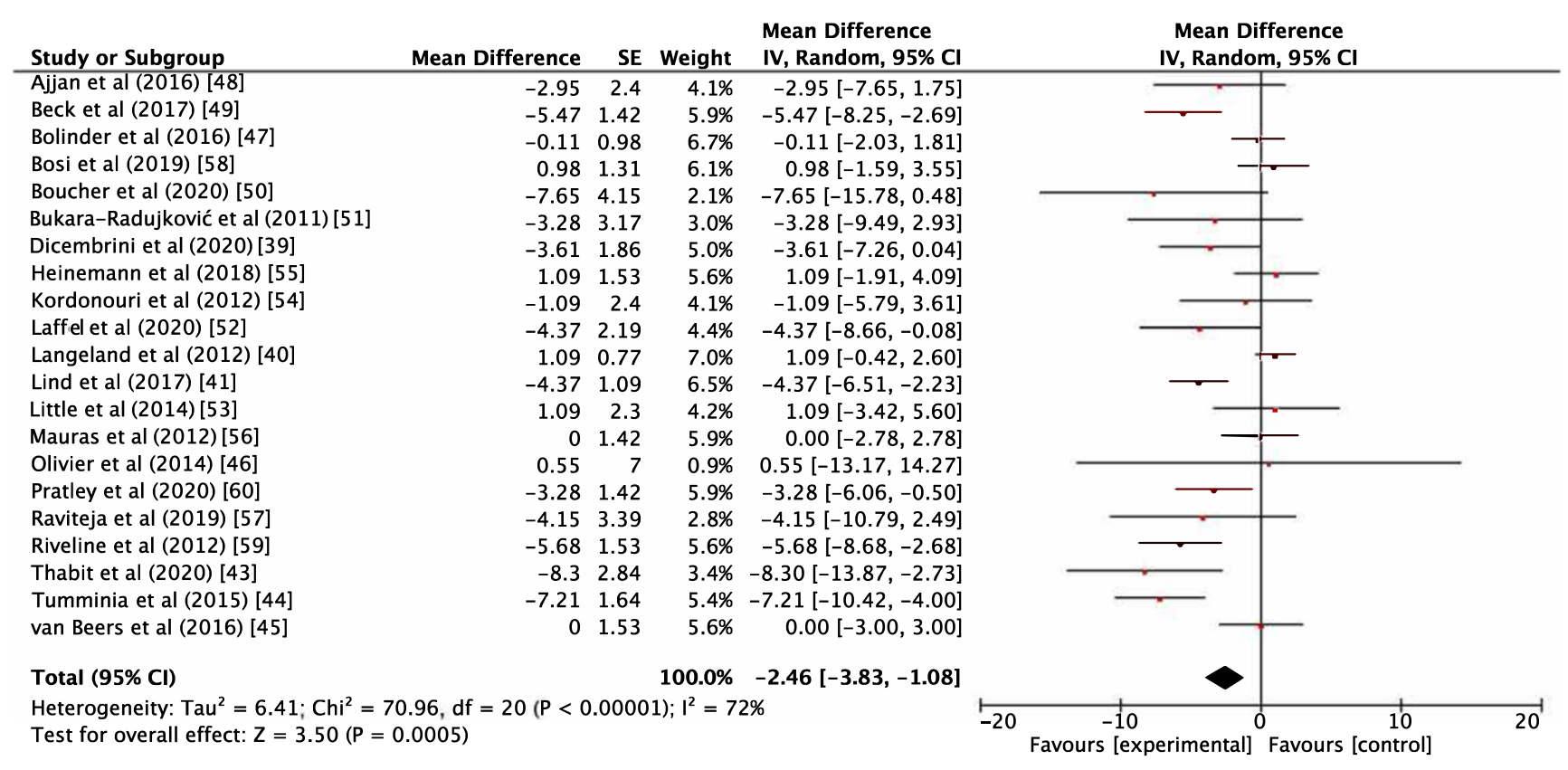

Fig. 1 Forest plot showing the effect of CGM on post-intervention $\mathrm{HbA}_{1 \mathrm{c}}(\mathrm{mmol} / \mathrm{mol})$. IV, inverse variance 


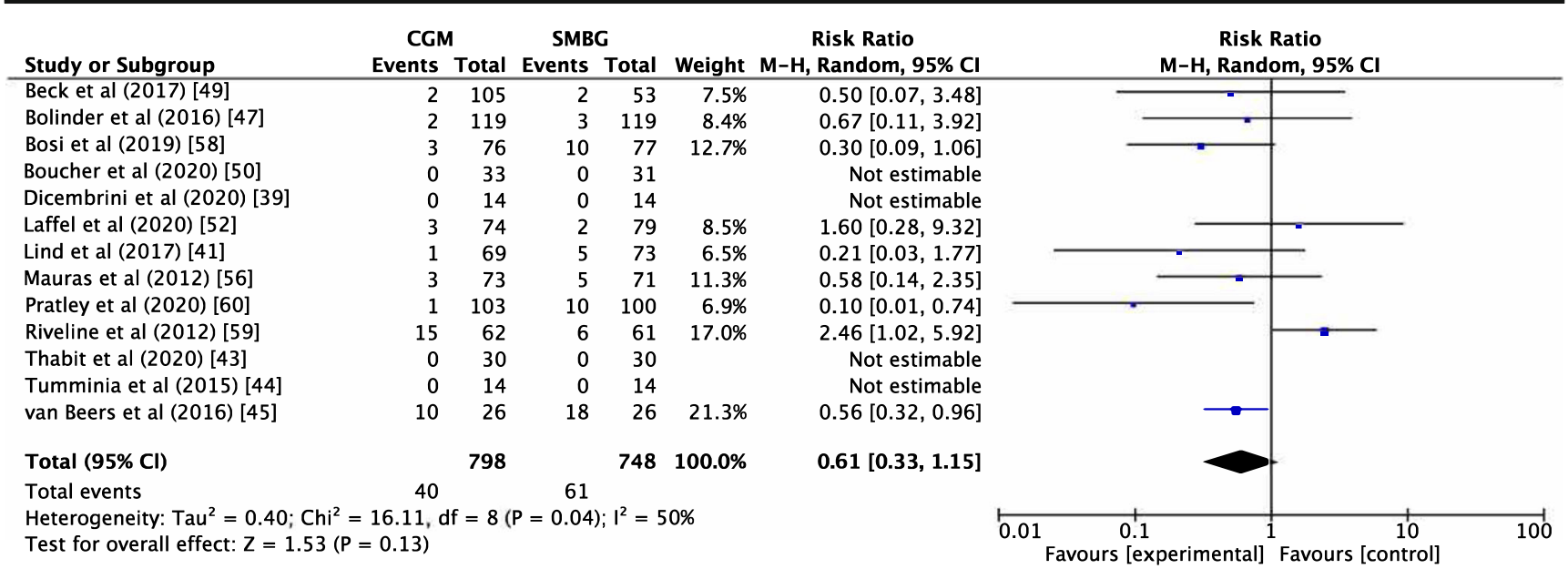

Fig. 2 Forest plot showing the effect of CGM on severe hypoglycaemia events. M-H, Mantel-Haenszel

$p=0.54)$ or unreported $\mathrm{HbA}_{1 \mathrm{c}}(Z=1.15, p=0.25)$ when compared with SMBG. Additionally, subgroup analysis comparing the effect of CGM among participants who utilised MDI, CSII and MDI/CSII insulin regimens revealed significant subgroup difference $\left(I^{2}=66.4 \%, p=0.05\right)$ (Fig. 5). Compared with $\mathrm{SMBG}$, significant reduction in $\mathrm{HbA}_{1 \mathrm{c}}$ level was experienced by individuals using CGM who were on MDI (MD $-2.66 \mathrm{mmol} / \mathrm{mol}[-0.24 \%$ ] [95\% CI -4.90 , $-0.42] ; Z=2.33, p=0.02$ ) and MDI/CSII (MD $-2.98 \mathrm{mmol} /$ $\operatorname{mol}[-0.27 \%][95 \% \mathrm{CI}-5.03,-0.92] ; Z=2.84, p=0.004)$. However, individuals on CSII experienced non-significant reduction in $\mathrm{HbA}_{1 \mathrm{c}}$ level $(Z=0.45, p=0.66)$.

\section{Meta-regression}

Meta-regression was conducted with baseline $\mathrm{HbA}_{1 \mathrm{c}}$ as the covariate. The regression coefficient was $-2.31 \mathrm{mmol} / \mathrm{mol}$ (95\% CI $-3.76,-0.86, p=0.0017)$, indicating that baseline $\mathrm{HbA}_{1 \mathrm{c}}$ was significantly associated with the MD.

\section{Sensitivity analysis}

Sensitivity analysis was conducted to observe whether removing any single study could reduce heterogeneity. No significant change in results or heterogeneity was observed.

\section{Publication bias}

Visual inspection of funnel plot on $\mathrm{HbA}_{1 \mathrm{c}}$ outcome (ESM Fig. 6) appeared to be symmetrical, and a non-significant Egger's test $(p=0.212)$ indicated a lack of publication bias. Visual inspection of funnel plot on secondary outcomes appeared symmetrical, suggesting no publication bias.

\section{GRADE assessment}

The GRADE criteria were adhered to [63], and the certainty of evidence for all outcomes was moderate (summarised in ESM

\begin{tabular}{|c|c|c|c|c|c|c|c|c|c|}
\hline Study or Subgroup & CGM & Total & \multicolumn{2}{|c|}{ SMBG } & Weight & Risk Ratio & & \multicolumn{2}{|c|}{$\begin{array}{c}\text { Risk Ratio } \\
\text { M-H, Random, 95\% Cl }\end{array}$} \\
\hline Beck et al (2017) [49] & 0 & 105 & 0 & 53 & & Not estimable & & & \\
\hline Bolinder et al (2016) [47] & 0 & 119 & 0 & 119 & & Not estimable & & & \\
\hline Bosi et al (2019) [58] & 0 & 76 & 0 & 77 & & Not estimable & & & \\
\hline Boucher et al (2020) [50] & 6 & 33 & 5 & 31 & $52.2 \%$ & $1.13[0.38,3.32]$ & & & \\
\hline Dicembrini et al (2020) [39] & 0 & 14 & 0 & 14 & & Not estimable & & & \\
\hline Laffel et al (2020) [52] & 3 & 74 & 1 & 79 & $12.1 \%$ & $3.20[0.34,30.11]$ & & & \\
\hline Lind et al (2017) [41] & 0 & 69 & 0 & 73 & & Not estimable & & & \\
\hline Little et al (2014) [53] & 0 & 48 & 3 & 48 & $7.1 \%$ & $0.14[0.01,2.69]$ & & & \\
\hline Mauras et al (2012) [56] & 0 & 74 & 0 & 72 & & Not estimable & & & \\
\hline Pratley et al (2020) [60] & 1 & 103 & 0 & 100 & $6.0 \%$ & $2.91[0.12,70.68]$ & & & \\
\hline Riveline et al (2012) [59] & 2 & 62 & 2 & 61 & $16.4 \%$ & $0.98[0.14,6.76]$ & & & \\
\hline Thabit et al (2020) [43] & 0 & 30 & 0 & 30 & & Not estimable & & & \\
\hline Tumminia et al (2015) [44] & 0 & 14 & 1 & 14 & $6.3 \%$ & $0.33[0.01,7.55]$ & & & \\
\hline van Beers et al (2016) [45] & 0 & 26 & 0 & 26 & & Not estimable & & & \\
\hline Total $(95 \% \mathrm{Cl})$ & & 847 & & 797 & $100.0 \%$ & $1.06[0.49,2.32]$ & & & \\
\hline Total events & 12 & & 12 & & & & & & \\
\hline $\begin{array}{l}\text { Heterogeneity: } \mathrm{Tau}^{2}=0.00 \\
\text { Test for overall effect: } Z=0\end{array}$ & $\begin{array}{l}3.70, \mathrm{df} \\
0.88)\end{array}$ & $=5(P$ & $=0.59)$ & $2=0$ & & & 0.01 & $\begin{array}{c}0.1 \\
\text { Favours [CGM] }\end{array}$ & Favours [SN \\
\hline
\end{tabular}

Fig. 3 Forest plot showing the effect of CGM on DKA events. M-H, Mantel-Haenszel 


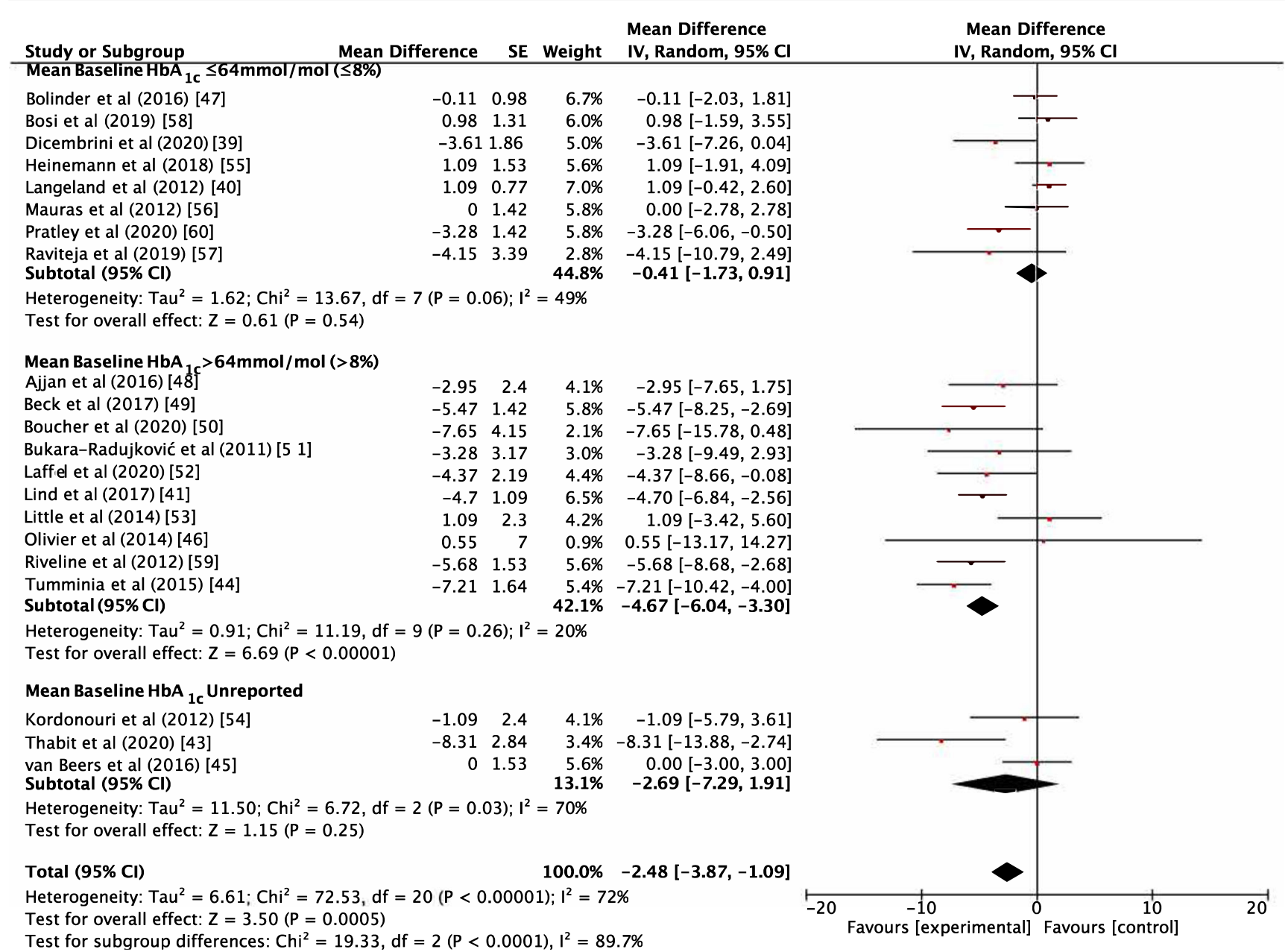

Fig. 4 Forest plot showing subgroup analysis of post-intervention $\mathrm{HbA}_{1 \mathrm{c}}(\mathrm{mmol} / \mathrm{mol})$ according to baseline $\mathrm{Hb} \mathrm{A}_{1 \mathrm{c}}$. IV, inverse variance

Table 3). All studies were RCTs and were graded 'not serious' for risk of bias as most of them were low risk. Certainty of evidence for $\mathrm{HbA}_{1 \mathrm{c}}$ level was downgraded due to inconsistency as substantial heterogeneity was observed. Certainty of evidence for severe hypoglycaemia was downgraded due to inconsistency as moderate heterogeneity was observed. Lastly, the certainty of evidence for DKA was downgraded due to imprecision as there were few DKA incidents observed.

\section{Discussion}

\section{Statement of principal findings}

Meta-analysis of 21 studies consisting of 2149 participants with type 1 diabetes mellitus evaluated the effectiveness of CGM compared with SMBG in glycaemic control. Findings revealed that CGM provided a superior benefit over SMBG in reducing $\mathrm{HbA}_{1 \mathrm{c}}$ level, with greater reduction seen in individuals with higher mean baseline $\mathrm{HbA}_{1 \mathrm{c}}$. CGM had no significant effect on severe hypoglycaemia and DKA events. While the influence of insulin regimens on the effectiveness of CGM remains unclear, the type of CGM system used, study duration and duration of diabetes did not significantly modify the effectiveness of CGM.

\section{Strengths and weaknesses of the study}

To our knowledge, this is the first meta-analysis to achieve the following: (1) finding significant benefits of CGM on $\mathrm{HbA}_{1 \mathrm{c}}$ among individuals with poor glycaemic control $\left(\mathrm{HbA}_{1 \mathrm{c}}>64 \mathrm{mmol} / \mathrm{mol}[>8 \%]\right)$; (2) finding significant association between baseline $\mathrm{HbA}_{1 \mathrm{c}}$ and effect size; and (3) evaluation of the effectiveness of isCGM in individuals with type 1 diabetes. These additional findings provide new evidence to a recent review [20] and an update of a prior review [19]. Furthermore, no publication bias was reported despite applying date restrictions in the search. This enhances the validity of the current findings [64]. Additionally, most of the included studies had similarly high methodological quality ratings, 


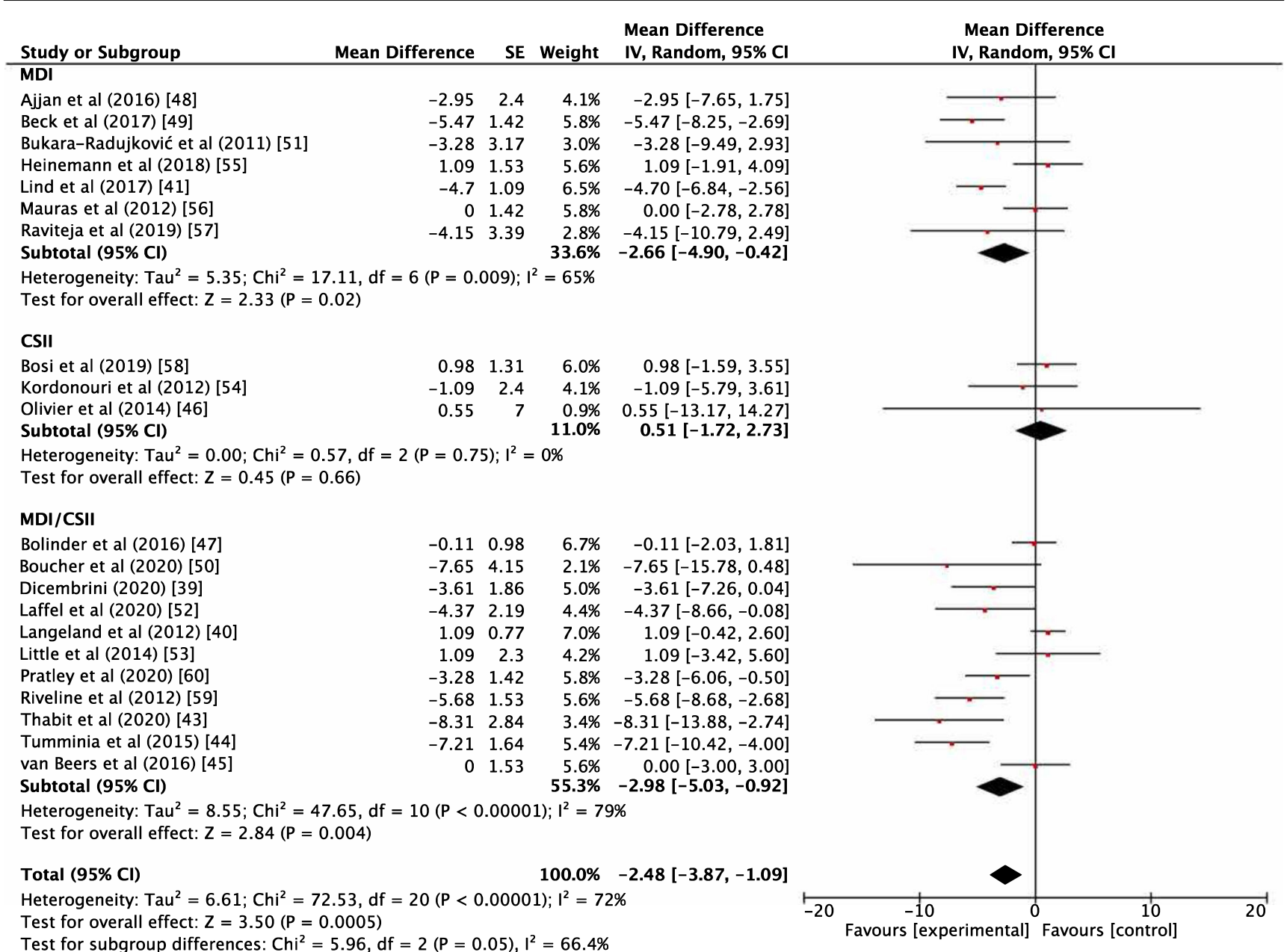

Fig. 5 Forest plot showing subgroup analysis of post-intervention $\mathrm{HbA}_{1 \mathrm{c}}(\mathrm{mmol} / \mathrm{mol})$ according to insulin regimen. IV, inverse variance

suggesting low methodological heterogeneity. Thus, it is unlikely that the studies were affected by various biases. Moreover, this paper identified participants' differing baseline $\mathrm{HbA}_{1 \mathrm{c}}$ as the source of substantial heterogeneity. Identification of this factor allows future studies to be designed better to obtain a more accurate CGM effect.

Studies reported that the effectiveness of CGM in controlling $\mathrm{HbA}_{1 \mathrm{c}}$ varies significantly across different age groups [65]. However, the influence of age on the effectiveness of CGM remains unclear in this paper. Subgroup analysis on age (i.e. children, adults, young adults, mixed population) was not possible as some subgroups would be represented in only one study. This prevented any meaningful comparisons from being made [66].

\section{Strengths and weaknesses in relation to other studies}

$\mathrm{HbA}_{1 c}$ level Use of CGM, compared with SMBG, led to an overall significant reduction in $\mathrm{HbA}_{1 \mathrm{c}}$ level, consistent with findings of previous studies wherein CGM resulted in a significant decrease in $\mathrm{HbA}_{1 \mathrm{c}}$ level unlike SMBG [15-17, 19, 21-23]. This finding was expected as CGM can produce abundant data on users' blood glucose levels compared with SMBG. The additional information derived from CGM enables a more granular analysis to guide treatment decisions, which could eventually improve glycaemic control [67]. However, two reviews have previously reported that CGM did not significantly lower $\mathrm{HbA}_{1 \mathrm{c}}$ levels compared with SMBG [14, 18]. The differing findings could be due to the low statistical power yielded by the small sample size in both reviews. Low-powered studies reportedly produced more false-negative results than high-powered studies [24]. Moreover, their findings could be biased as most of the included studies were of low methodological quality [68]. Our review incorporated 17 additional new studies [39-44, 46, $48,50-54,56,57,59,60]$ compared with a prior review [20] which shared five common studies [45, 47, 49, 55, 58] with the current paper. Current findings also revealed a larger effect estimate (i.e. $\mathrm{HbA}_{1 \mathrm{c}}$ decrease) of $-2.46 \mathrm{mmol} / \mathrm{mol}$ $(-0.23 \%)(95 \% \mathrm{CI}-3.83,-1.08, p=0.0005)$ as compared with 
the prior review which reported a $\mathrm{HbA}_{1 \mathrm{c}}$ decrease of $-1.75 \mathrm{mmol} / \mathrm{mol}(-0.16 \%)(95 \% \mathrm{CI}-2.79,-0.71, p<0.001)$ [20].

Severe hypoglycaemia and DKA events CGM intervention, relative to SMBG, did not significantly reduce the number of severe hypoglycaemia events. Although these findings concurred with those of three other reviews [19, 21, 22], a recent study reported that CGM significantly lowers the risk of severe hypoglycaemia compared with SMBG [15]. The mixed findings could be attributed to a methodological limitation found in this paper along with the other three reviews $[19,21,22]$. Compared with the aforementioned study [15], the relatively smaller sample arms seen in the four papers on the severe hypoglycaemia outcome yields low statistical power which increases the likelihood of false-negative results [24].

Although CGM reportedly had no significant effect on the number of DKA events, in comparison with SMBG, the current result must be interpreted with caution due to insufficient data. The finding was anticipated to produce the same conclusion as the other previous studies [15, 22, 23]. In all four reviews, including this study, DKA incidents were rare. Meta-analysis of rare events can produce misleading results [37]. Hence, this review could not confer a concrete conclusion on the effectiveness of CGM.

\section{Subgroup analyses}

Significant subgroup difference was only observed in the subgroup analyses stratified according to participants' mean baseline $\mathrm{HbA}_{1 \mathrm{c}}(\leq 64 \mathrm{mmol} / \mathrm{mol}[\leq 8 \%],>64 \mathrm{mmol} / \mathrm{mol}[>8 \%]$ and unreported) and insulin regimen (MDI, CSII and MDI/ CSII). In participants with mean baseline $\mathrm{HbA}_{1 \mathrm{c}}>64 \mathrm{mmol} /$ $\mathrm{mol}(>8 \%)$, those using CGM experienced a significant reduction in $\mathrm{HbA}_{1 \mathrm{c}}$ level relative to those using $\mathrm{SMBG}$, unlike those with mean baseline $\mathrm{HbA}_{1 \mathrm{c}} \leq 64 \mathrm{mmol} / \mathrm{mol}(\leq 8 \%)$. Notably, $\mathrm{HbA}_{1 \mathrm{c}}>64 \mathrm{mmol} / \mathrm{mol}(>8 \%$ ) indicates poor glycaemic control [69]. This phenomenon could be attributed to the tendency of individuals with type 1 diabetes to maintain high glucose levels to avoid hypoglycaemia [70]. This behaviour could be more apparent in individuals with poor glycaemic control since their $\mathrm{HbA}_{1 \mathrm{c}}$ level is higher. As CGM reportedly reduces fear of hypoglycaemia among individuals with type 1 diabetes [71], the need to maintain a high glucose level might be eliminated, especially among individuals with poor glycaemic control. Hence, such individuals may experience greater $\mathrm{HbA}_{1 \mathrm{c}}$ reduction using CGM. Moreover, overall heterogeneity $\left(I^{2}=72 \%\right)$ appears to be caused by clinical heterogeneity. This could be a result of the differing mean baseline $\mathrm{HbA}_{1 \mathrm{c}}$ levels of participants. Differing heterogeneity between subgroups with mean baseline $\mathrm{HbA}_{1 \mathrm{c}} \leq 64 \mathrm{mmol} / \mathrm{mol}(\leq 8 \%)\left(I^{2}=49 \%\right)$ and mean baseline $\mathrm{HbA}_{1 \mathrm{c}}>64 \mathrm{mmol} / \mathrm{mol}(>8 \%)\left(I^{2}=20 \%\right)$ could be attributed to the difference in behaviour between subgroups. In the subgroup with unreported $\mathrm{HbA}_{1 \mathrm{c}}$ levels, the substantial heterogeneity $\left(I^{2}=70 \%\right)$ observed may be caused by the wide variation in baseline $\mathrm{HbA}_{1 \mathrm{c}}$ in the studies. Results from the meta-regression also indicated that the baseline $\mathrm{HbA}_{1 \mathrm{c}}$ was significantly associated with the effect size. This further suggests that individuals with type 1 diabetes with $\mathrm{HbA}_{1 \mathrm{c}}$ $>64 \mathrm{mmol} / \mathrm{mol}(>8 \%)$ are most likely to benefit from CGM.

Although a significant subgroup effect was observed for participants' insulin regimen, the overall evidence on glycaemic control was conflicting. Compared with SMBG users, participants using CGM who were on MDI and MDI/ CSII experienced significantly lower $\mathrm{HbA}_{1 \mathrm{c}}$ levels, unlike those on CSII. This analysis is likely to be unreliable for conferring a clear effect of CGM influenced by insulin regimen on $\mathrm{HbA}_{1 \mathrm{c}}$ as a far smaller number of trials and participants was observed in the CSII subgroup ( $n=3$ studies, 304 participants) than in the MDI ( $n=7$ trials, 804 participants) and MDI/CSII ( $n=11$ trials, 1041 participants) subgroups. Due to uneven covariate distribution, the validity of the findings was, therefore, hindered [66].

\section{Implications of findings}

Current findings revealed an $\mathrm{MD}$ in $\mathrm{HbA}_{1 \mathrm{c}}$ levels of $-2.46 \mathrm{mmol} / \mathrm{mol}(-0.23 \%)$ between CGM and SMBG. Although it may appear insubstantial, the DCCT trial found that a decrease in $\mathrm{HbA}_{1 \mathrm{c}}$ level (regardless of magnitude) was always accompanied by a reduction in diabetic complication risk [72]. Furthermore, with the larger MD of $-4.67 \mathrm{mmol} /$ $\mathrm{mol}(-0.43 \%)$ observed in individuals with $\mathrm{HbA}_{1 \mathrm{c}}>64 \mathrm{mmol} /$ mol ( $>8 \%)$, CGM could substantially lower macrovascular risk among individuals with poor glycaemic control since elevated $\mathrm{HbA}_{1 \mathrm{c}}$ level $(>59 \mathrm{mmol} / \mathrm{mol}[>7.5 \%])$ is correlated with higher cardiovascular disease and mortality risk [73]. This further suggests that CGM is a superior method for monitoring glucose, compared with SMBG, for the type 1 diabetes mellitus population. In all, individuals with type 1 diabetes, especially those with poorly controlled diabetes, are strongly encouraged to use CGM instead of SMBG.

This paper may be relevant to clinicians providing outpatient services. As all studies were conducted in an outpatient setting, the present findings suggest that CGM is effective in managing glycaemic control in the community.

\section{Future research and practice}

The effectiveness of CGM systems in the long term and their relationship with diabetes complications requires more comprehensive follow-up studies. Future research could investigate the effectiveness of CGM across different age groups and insulin regimens since not much is known. 
Moreover, this review presented limited evidence to support ongoing research (e.g. the use of an artificial pancreas, a combined treatment consisting of CGM, insulin pump and software algorithm that automates glycaemic control). The accuracy of CGM is essential for the safety of the artificial pancreas. It is measured using the mean absolute relative difference (MARD) between CGM glucose value and a reference value (i.e. SMBG) [70]. As none of the included studies reported MARD, future studies could evaluate CGM's accuracy using MARD as an outcome. A recent consensus statement by the Diabetes Technology Society reported that inpatient CGM usage improved overall glycaemic control [74]. As current evidence is limited to the outpatient setting, future studies could be conducted in an inpatient setting.

Current clinical guidelines support the use of CGM in the management of type 1 diabetes $[75,76]$. New findings in this paper indicate that individuals with $\mathrm{HbA}_{1 \mathrm{c}}>64 \mathrm{mmol} / \mathrm{mol}$ $(>8 \%)$ would benefit most from CGM, coupled with a moderate certainty of evidence. This could further encourage clinicians to recommend CGM as the main monitoring method for the type 1 diabetes population, especially those with poor glycaemic control.

\section{Conclusion}

This systematic review and meta-analysis shows that CGM improves glycaemic control (expressed as $\mathrm{HbA}_{1 \mathrm{c}}$ level) in individuals with type 1 diabetes, with the new finding that those with poor glycaemic control $\left(\mathrm{HbA}_{1 \mathrm{c}}>64 \mathrm{mmol} / \mathrm{mol}\right.$ [>8\%]) especially benefit. However, CGM did not affect severe hypoglycaemia and DKA events. Nonetheless, compelling evidence from this review suggests that individuals with type 1 diabetes with $\mathrm{HbA}_{1 \mathrm{c}}>64 \mathrm{mmol} / \mathrm{mol} \mathrm{(>8 \% )}$ would benefit most from CGM compared with SMBG. The present findings may serve as a foundation for future studies to evaluate CGM's accuracy, and the influence of user's age and insulin regimen on the effectiveness of CGM.

Supplementary Information The online version contains peer-reviewed but unedited supplementary material available at https://doi.org/10.1007/ s00125-021-05648-4.

\begin{abstract}
Acknowledgements We would like to thank I. Noreen for editorial assistance. I. Noreen is a senior assistant manager of the Medical \& Scientific Communication, Research Support Unit under the National University Health System, Singapore. Additionally, we would like to thank R. Ajjan and M. Lind for the clarification and provision of missing study information. R. Ajjan and M. Lind are authors of two studies included in the meta-analysis [41, 48].
\end{abstract}

Data availability All data generated or analysed during this study are included in this published article (and its supplementary information files). All $\mathrm{HbA}_{1 \mathrm{c}}$ values were converted using the formula on the National Glycohemoglobin Standardization Program website (http:// www.ngsp.org/ifcc.asp).
Funding This research received no specific grant from any funding agency in the public, commercial or not-for-profit sectors.

Authors' relationships and activities The authors declare that there are no relationships or activities that might bias, or be perceived to bias, their work.

Contribution statement ET, WT and SK contributed to the study design, main concept, statistical analysis and interpretation of results. ET, NH and SK developed the protocol. ET and SK were responsible for the study selection and data extraction. NH resolved discrepancies between reviewers on text selection and data extraction. ET drafted the paper and NH, WT and SK revised the manuscript for important intellectual content. All authors read and approved the final draft before submission. ET is the guarantor of this work.

\section{References}

1. Tuomilehto J (2013) The emerging global epidemic of type 1 diabetes. Curr Diabetes Rep 13(6):795-804. https://doi.org/10.1007/ s11892-013-0433-5

2. Tao B, Pietropaolo M, Atkinson M, Schatz D, Taylor D (2010) Estimating the cost of type 1 diabetes in the U.S.: a propensity score matching method. PLoS One 5(7):Article e11501. https://doi.org/ 10.1371/journal.pone.0011501

3. Sussman M, Benner J, Haller MJ, Rewers M, Griffiths R (2020) Estimated lifetime economic burden of type 1 diabetes. Diabetes Technol Ther 22(2):121-130. https://doi.org/10.1089/dia.2019. 0398

4. Secrest AM, Washington RE, Orchard TJ. Mortality in Type 1 Diabetes. In: Cowie CC, Casagrande SS, Menke A, et al, editors. Diabetes in America. 3rd edition. Bethesda (MD): National Institute of Diabetes and Digestive and Kidney Diseases (US); 2018 Aug. CHAPTER 35. Available from: https://www.ncbi.nlm.nih.gov/books/ NBK567986/

5. Nathan DM, Genuth S, Lachin J et al (1993) The effect of intensive treatment of diabetes on the development and progression of long-term complications in insulin-dependent diabetes mellitus. N Engl J Med 329(14):977-986. https://doi.org/10.1056/nejm199309303291401

6. Malik FS, Taplin CE (2014) Insulin therapy in children and adolescents with type 1 diabetes. Paediatr Drugs 16(2):141-150. https:// doi.org/10.1007/s40272-014-0064-6

7. American Diabetes Association (2019) Glycemic targets: standards of medical care in diabetes-2019. Diabetes Care 42(Supplement 1):S61-S70. https://doi.org/10.2337/dc19-S006

8. Leszek C, László B, Svetlana B et al (2014) Self-monitoring of blood glucose in diabetes: from evidence to clinical reality in Central and Eastern Europe - recommendations from the international Central-eastern European expert group. Diabetes Technol Ther 16(7):460-475

9. Edelman SV, Argento NB, Pettus J, Hirsch IB (2018) Clinical implications of real-time and intermittently scanned continuous glucose monitoring. Diabetes Care 41(11):2265-2274. https://doi. org/10.2337/dc18-1150

10. Ajjan R, Slattery D, Wright E (2019) Continuous glucose monitoring: a brief review for primary care practitioners. Adv Ther 36(3): 579-596. https://doi.org/10.1007/s12325-019-0870-x

11. National Institute of Health (2017) Continuous Glucose Monitoring. Available from https://www.niddk.nih.gov/healthinformation/diabetes/overview/managing-diabetes/continuousglucose-monitoring. Accessed 3 July 2020 
12. Reddy N, Verma N, Dungan K (2020) Monitoring technologies Continuous glucose monitoring, mobile technology, biomarkers of glycemic control. In: Feingold KR, Anawalt B, Boyce A, et al. (eds) Endotext MDText.com, Inc., South Dartmouth (MA)

13. Adolfsson P, Parkin CG, Thomas A, Krinelke LG (2018) Selecting the appropriate continuous glucose monitoring system - a practical approach. Eur Endocrinol 14(1):24-29. https://doi.org/10.17925/ ee.2018.14.1.24

14. Chetty VT, Almulla A, Odueyungbo A, Thabane L (2008) The effect of continuous subcutaneous glucose monitoring (CGMS) versus intermittent whole blood finger-stick glucose monitoring (SBGM) on hemoglobin A1c (HBA1c) levels in type I diabetic patients: a systematic review. Diabetes Res Clin Pract 81(1):7987. https://doi.org/10.1016/j.diabres.2008.02.014

15. Dicembrini I, Cosentino C, Monami M, Mannucci E, Pala L (2021) Effects of real-time continuous glucose monitoring in type 1 diabetes: a meta-analysis of randomized controlled trials. Acta Diabetol 58:401-410. https://doi.org/10.1007/s00592-020-01589-3

16. Floyd B, Chandra P, Hall S et al (2012) Comparative analysis of the efficacy of continuous glucose monitoring and self-monitoring of blood glucose in type 1 diabetes mellitus. J Diabetes Sci Technol 6(5):1094-1102. https://doi.org/10.1177/193229681200600513

17. Gandhi GY, Kovalaske M, Kudva Y et al (2011) Efficacy of continuous glucose monitoring in improving glycemic control and reducing hypoglycemia: a systematic review and meta-analysis of randomized trials. J Diabetes Sci Technol 5(4):952-965. https:// doi.org/10.1177/193229681100500419

18. Golicki DT, Golicka D, Groele L, Pankowska E (2008) Continuous glucose monitoring system in children with type 1 diabetes mellitus: a systematic review and meta-analysis. Diabetologia 51(2):233-240. https://doi.org/10.1007/s00125-007-0884-9

19. Langendam M, Luijf YM, Hooft L, Devries JH, Mudde AH, Scholten RJ (2012) Continuous glucose monitoring systems for type 1 diabetes mellitus. Cochrane Database Syst Rev 1(1). https://doi.org/10.1002/14651858.CD008101.pub2

20. Maiorino MI, Signoriello S, Maio A et al (2020) Effects of continuous glucose monitoring on metrics of glycemic control in diabetes: a systematic review with meta-analysis of randomized controlled trials. Diabetes Care 43(5):1146-1156. https://doi.org/10.2337/ dc19-1459

21. Pickup JC, Freeman SC, Sutton AJ (2011) Glycaemic control in type 1 diabetes during real time continuous glucose monitoring compared with self monitoring of blood glucose: Meta-analysis of randomised controlled trials using individual patient data. Br Med J 343:3805. https://doi.org/10.1136/bmj.d3805

22. Szypowska A, Ramotowska A, Dzygalo K, Golicki D (2012) Beneficial effect of real-time continuous glucose monitoring system on glycemic control in type 1 diabetic patients: systematic review and meta-analysis of randomized trials. Eur J Endocrinol 166(4):567-574. https://doi.org/10.1530/eje-11-0642

23. Wojciechowski P, Ryś P, Lipowska A, Gawęska M, Małecki MT (2011) Efficacy and safety comparison of continuous glucose monitoring and self-monitoring of blood glucose in type 1 diabetes: systematic review and meta-analysis. Pol Arch Med Wewn 121(10):333-343

24. Button KS, Ioannidis JP, Mokrysz C et al (2013) Power failure: why small sample size undermines the reliability of neuroscience. Nat Rev Neurosci 14(5):365-376. https://doi.org/10.1038/nrn3475

25. Paez A (2017) Gray literature: an important resource in systematic reviews. J Evid-Based Med 10(3):233-240. https://doi.org/10. $1111 /$ jebm. 12266

26. Leelarathna L, Wilmot EG (2018) Flash forward: a review of flash glucose monitoring. Diabet Med 35(4):472-482. https://doi.org/10. $1111 /$ dme. 13584

27. Lefebvre C, Glanville J, Briscoe S et al (2019) Chapter 4: Searching for and selecting studies. In: Higgins JPT, Green S (eds) (2011)
Cochrane handbook for systematic reviews of interventions 5.1.0 [updated March 2011]. The Cochrane Collaboration, pp 67-107. Available from www.Cochrane-handbook.org (or updated version when available: see http://training.cochrane.org/handbook)

28. Weisman A, Bai JW, Cardinez M, Kramer CK, Perkins BA (2017) Effect of artificial pancreas systems on glycaemic control in patients with type 1 diabetes: a systematic review and meta-analysis of outpatient randomised controlled trials. Lancet Diabetes Endocrinol 5(7):501-512. https://doi.org/10.1016/s2213-8587(17) 30167-5

29. Liberati A, Altman DG, Tetzlaff J et al (2009) The PRISMA statement for reporting systematic reviews and meta-analyses of studies that evaluate healthcare interventions: explanation and elaboration. Br Med J 339:b2700. https://doi.org/10.1136/bmj.b2700

30. Villena Gonzales W, Mobashsher AT, Abbosh A (2019) The progress of glucose monitoring - a review of invasive to minimally and non-invasive techniques, devices and sensors. Sensors 19(4):800. https://doi.org/10.3390/s19040800

31. Clarivate Analytics (2020) Endnote. Available from https:// endnote.com/. Accessed 22 December 2020

32. Higgins JPT, Green S (2011) Cochrane handbook for systematic reviews of interventions version 5.1.0 [updated March 2011]. The Cochrane Collaboration. Available from www.Cochranehandbook.org (or updated version when available: see http:// training.cochrane.org/handbook)

33. GraphPad Software (2021) Kappa quantify interrater agreement were calculated using the GraphPad QuickCalcs. Available from https://www.graphpad.com/quickcalcs/kappa1/. Accessed 29 December 2020

34. Review Manager (RevMan) [Computer program]. Version 5.4.1. The Cochrane Collaboration, 2020

35. R Foundation for Statistical Computing (2020) R: A Language and Environment for Statistical Computing. Available from https:// www.R-project.org/. Accessed 17 October 2021

36. Egger M, Smith GD, Schneider M, Minder C (1997) Bias in metaanalysis detected by a simple, graphical test. Br Med J 315(7109): 629-634. https://doi.org/10.1136/bmj.315.7109.629

37. Deeks JJ, Higgins JPT, Altman DG (2019) Chapter 10: Analysing data and undertaking meta-analyses. In: Higgins JPT, Green S (eds) (2011) Cochrane handbook for systematic reviews of interventions 5.1.0 [updated March 2011]. The Cochrane Collaboration, pp 241284. Available from www.Cochrane-handbook.org (or updated version when available: see http://training.cochrane.org/handbook)

38. GRADEpro GDT (2020) GRADEpro Guideline Development Tool. In: McMaster University and Evidence Prime, Inc, Hamilton, Canada

39. Dicembrini I, Pala L, Caliri M et al (2020) Combined continuous glucose monitoring and subcutaneous insulin infusion versus selfmonitoring of blood glucose with optimized multiple injections in people with type 1 diabetes: a randomized crossover trial. Diabetes Obes Metab 22(8):1286-1291. https://doi.org/10.1111/dom.14028

40. Langeland LBL, Salvesen O, Selle H, Carlsen SM, Fougner KJ (2012) Short-term continuous glucose monitoring: effects on glucose and treatment satisfaction in patients with type 1 diabetes mellitus; a randomized controlled trial. Int J Clin Pract 66(8):741747. https://doi.org/10.1111/j.1742-1241.2012.02947.x

41. Lind M, Polonsky W, Hirsch IB et al (2017) Continuous glucose monitoring vs conventional therapy for glycemic control in adults with type 1 diabetes treated with multiple daily insulin injections: the GOLD randomized clinical trial. J Am Med Assoc 317(4):379 387. https://doi.org/10.1001/jama.2016.19976

42. Sequeira PA, Montoya L, Ruelas V et al (2013) Continuous glucose monitoring pilot in low-income type 1 diabetes patients. Diabetes Technol Ther 15(10):855-858. https://doi.org/10.1089/dia.2013. 0072 
43. Thabit H, Prabhu JN, Mubita W et al (2020) Use of factorycalibrated real-time continuous glucose monitoring improves time in target and $\mathrm{HbAlc}$ in a multiethnic cohort of adolescents and young adults with type 1 diabetes: the MILLENNIALS study. Diabetes Care 43(10):2537-2543. https://doi.org/10.2337/dc200736

44. Tumminia A, Crimi S, Sciacca L et al (2015) Efficacy of real-time continuous glucose monitoring on glycaemic control and glucose variability in type 1 diabetic patients treated with either insulin pumps or multiple insulin injection therapy: a randomized controlled crossover trial. Diabetes Metab Res Rev 31(1):61-68. https://doi.org/10.1002/dmrr.2557

45. van Beers CA, DeVries JH, Kleijer SJ et al (2016) Continuous glucose monitoring for patients with type 1 diabetes and impaired awareness of hypoglycaemia (IN CONTROL): a randomised, open-label, crossover trial. Lancet Diabetes Endocrinol 4(11): 893-902. https://doi.org/10.1016/s2213-8587(16)30193-0

46. Olivier P, Lawson ML, Huot C, Richardson C, Nakhla M, Romain J (2014) Lessons learned from a pilot rct of simultaneous versus delayed initiation of continuous glucose monitoring in children and adolescents with type 1 diabetes starting insulin pump therapy. J Diabetes Sci Technol 8(3):523-528. https://doi.org/10.1177/ 1932296814524855

47. Bolinder J, Antuna R, Geelhoed-Duijvestijn P, Kröger J, Weitgasser R (2016) Novel glucose-sensing technology and hypoglycaemia in type 1 diabetes: a multicentre, non-masked, randomised controlled trial. Lancet 388(10057):2254-2263. https://doi.org/10.1016/s0140-6736(16)31535-5

48. Ajjan RA, Abougila K, Bellary S et al (2016) Sensor and software use for the glycaemic management of insulin-treated type 1 and type 2 diabetes patients. Diab Vasc Dis Res 13(3):211-219. https://doi.org/10.1177/1479164115624680

49. Beck RW, Riddlesworth T, Ruedy K et al (2017) Effect of continuous glucose monitoring on glycemic control in adults with type 1 diabetes using insulin injections: the DIAMOND randomized clinical trial. J Am Med Assoc 317(4):371-378. https://doi.org/10. 1001/jama.2016.19975

50. Boucher SE, Gray AR, Wiltshire EJ et al (2020) Effect of 6 months of flash glucose monitoring in youth with type 1 diabetes and highrisk glycemic control: a randomized controlled trial. Diabetes Care 43(10):2388-2395. https://doi.org/10.2337/dc20-0613

51. Bukara-Radujković G, Zdravković D, Lakić S (2011) Short-term use of continuous glucose monitoring system adds to glycemic control in young type 1 diabetes mellitus patients in the long run: a clinical trial. Vojnosanit Pregl 68(8):650-654. https://doi.org/10. 2298/vsp1108650b

52. Laffel LM, Kanapka LG, Beck RW et al (2020) Effect of continuous glucose monitoring on glycemic control in adolescents and young adults with type 1 diabetes: a randomized clinical trial. J Am Med Assoc 323(23):2388-2396. https://doi.org/10.1001/ jama.2020.6940

53. Little SA, Leelarathna L, Walkinshaw E et al (2014) Recovery of hypoglycemia awareness in long-standing type 1 diabetes: a multicenter $2 \times 2$ factorial randomized controlled trial comparing insulin pump with multiple daily injections and continuous with conventional glucose self-monitoring (HypoCOMPaSS). Diabetes Care 37(8):2114-2122. https://doi.org/10.2337/dc14-0030

54. Kordonouri O, Hartmann R, Pankowska E et al (2012) Sensor augmented pump therapy from onset of type 1 diabetes: late follow-up results of the pediatric onset study. Pediatr Diabetes 13(7):515-518. https://doi.org/10.1111/j.1399-5448.2012.00863.x

55. Heinemann L, Freckmann G, Ehrmann D et al (2018) Real-time continuous glucose monitoring in adults with type 1 diabetes and impaired hypoglycaemia awareness or severe hypoglycaemia treated with multiple daily insulin injections (HypoDE): a multicentre, randomised controlled trial. Lancet 391(10128):1367-1377. https:// doi.org/10.1016/s0140-6736(18)30297-6

56. Mauras N, Beck R, Xing D et al (2012) A randomized clinical trial to assess the efficacy and safety of real-time continuous glucose monitoring in the management of type 1 diabetes in young children aged 4 to $<10$ years. Diabetes Care 35(2):204-210. https://doi.org/ $10.2337 / \mathrm{dc} 11-1746$

57. Raviteja KV, Kumar R, Dayal D, Sachdeva N (2019) Clinical efficacy of professional continuous glucose monitoring in improving glycemic control among children with type 1 diabetes mellitus: an open-label randomized control trial. Sci Rep 9(1):6120. https://doi. org/10.1038/s41598-019-42555-6

58. Bosi E, Choudhary P, de Valk HW et al (2019) Efficacy and safety of suspend-before-low insulin pump technology in hypoglycaemiaprone adults with type 1 diabetes (SMILE): an open-label randomised controlled trial. Lancet Diabetes Endocrinol 7(6): 462-472. https://doi.org/10.1016/s2213-8587(19)30150-0

59. Riveline JP, Schaepelynck P, Chaillous L et al (2012) Assessment of patient-led or physician-driven continuous glucose monitoring in patients with poorly controlled type 1 diabetes using basal-bolus insulin regimens: a 1-year multicenter study. Diabetes Care 35(5): 965-971. https://doi.org/10.2337/dc11-2021

60. Pratley RE, Kanapka LG, Rickels MR et al (2020) Effect of continuous glucose monitoring on hypoglycemia in older adults with type 1 diabetes: a randomized clinical trial. Jama 323(23):2397-2406. https://doi.org/10.1001/jama.2020.6928

61. Moustgaard H, Bello S, Miller FG, Hróbjartsson A (2014) Subjective and objective outcomes in randomized clinical trials: definitions differed in methods publications and were often absent from trial reports. J Clin Epidemiol 67(12):1327-1334. https://doi. org/10.1016/j.jclinepi.2014.06.020

62. Schulz KF, Grimes DA (2002) Sample size slippages in randomised trials: exclusions and the lost and wayward. Lancet 359(9308):781-785. https://doi.org/10.1016/s0140-6736(02) 07882-0

63. Schünemann HJ, Vist GE, Higgins JPT et al (2019) Chapter 15: Interpreting results and drawing conclusions. In: Higgins JPT, Green S (eds) (2011) Cochrane handbook for systematic reviews of interventions 5.1.0 [updated March 2011]. The Cochrane Collaboration, pp 403-431. Available from www.Cochranehandbook.org (or updated version when available: see http:// training.cochrane.org/handbook)

64. van Aert RCM, Wicherts JM, van Assen MALM (2019) Publication bias examined in meta-analyses from psychology and medicine: a meta-meta-analysis. PLoS One 14(4):Article e0215052. https://doi.org/10.1371/journal.pone.0215052

65. Weinzimer S, Miller K, Beck R et al (2010) Effectiveness of continuous glucose monitoring in a clinical care environment. Diabetes Care 33(1):17-22. https://doi.org/10.2337/dc09-1502

66. Richardson M, Garner P, Donegan S (2018) Interpretation of subgroup analyses in systematic reviews: a tutorial. Clin Epidemiol Glob Health 7:196. https://doi.org/10.1016/j.cegh. 2018.05.005

67. American Diabetes Association (2019) Diabetes technology: standards of medical care in diabetes-2019. Diabetes Care 42(Supplement 1):S71-S80. https://doi.org/10.2337/dc19-S007

68. Lee YH (2019) Strengths and limitations of meta-analysis. Korean J Med 94(5):391-395. https://doi.org/10.3904/kjm.2019.94.5.391

69. Sherwani SI, Khan HA, Ekhzaimy A, Masood A, Sakharkar MK (2016) Significance of HbA1c test in diagnosis and prognosis of diabetic patients. SAGE J 11:95-104. https://doi.org/10.4137/BMI. S 38440

70. Blauw H, Keith-Hynes P, Koops R, DeVries JH (2016) A review of safety and design requirements of the artificial pancreas. Ann Biomed Eng 44(11):3158-3172. https://doi.org/10.1007/s10439016-1679-2 
71. Juvenile Diabetes Research Foundation Continous Glucose Monitoring Study Group, Beck RW, Lawrence JM et al (2010) Quality-of-life measures in children and adults with type 1 diabetes: juvenile diabetes research foundation continuous glucose monitoring randomized trial. Diabetes Care 33(10):2175-2177. https://doi. org $/ 10.2337 / \mathrm{dc} 10-0331$

72. The Diabetes Control and Complications Trial Research Group (1996) The absence of a glycemic threshold for the development of long-term complications: the perspective of the diabetes control and complications trial. Diabetes 45(10):1289-1298. https://doi. org/10.2337/diab.45.10.1289

73. Chen Y-Y, Lin Y-J, Chong E et al (2015) The impact of diabetes mellitus and corresponding $\mathrm{HbAlc}$ levels on the future risks of cardiovascular disease and mortality: a representative cohort study in Taiwan. PLoS One 10(4):Article e0123116. https://doi.org/10. 1371/journal.pone.0123116

74. Wallia A, Umpierrez GE, Rushakoff RJ et al (2017) Consensus statement on inpatient use of continuous glucose monitoring. J
Diabetes Sci Technol 11(5):1036-1044. https://doi.org/10.1177/ 1932296817706151

75. Cosentino F, Grant PJ, Aboyans V et al (2019) 2019 ESC guidelines on diabetes, pre-diabetes, and cardiovascular diseases developed in collaboration with the EASD: the task force for diabetes, pre-diabetes, and cardiovascular diseases of the European Society of Cardiology (ESC) and the European Association for the Study of diabetes (EASD). Eur Heart J 41(2):255-323. https://doi.org/10. 1093/eurheartj/ehz486

76. American Diabetes Association (2021) 7. Diabetes technology: standards of medical Care in Diabetes-2021. Diabetes Care 44(Supplement 1):S85-S99. https://doi.org/10.2337/dc21-S007

Publisher's note Springer Nature remains neutral with regard to jurisdictional claims in published maps and institutional affiliations. 